\title{
Corrigendum
}

\section{Corrigendum to “On Interval-Valued Hesitant Fuzzy Soft Sets”}

\author{
Ahmed Mostafa Khalil, ${ }^{1}$ Haidong Zhang, ${ }^{2}$ Lianglin Xiong, ${ }^{3}$ and Weiyuan $\mathrm{Ma}^{2}$ \\ ${ }^{1}$ Department of Mathematics, Faculty of Science, Al-Azhar University, Assiut 71524, Egypt \\ ${ }^{2}$ School of Mathematics and Computer Science, Northwest University for Nationalities, Lanzhou, Gansu 730030, China \\ ${ }^{3}$ School of Mathematics and Computer Science, Yunnan Minzu University, Kunming, Yunnan 650500, China
}

Correspondence should be addressed to Ahmed Mostafa Khalil; a.khalil@azhar.edu.eg and Haidong Zhang; lingdianstar@163.com

Received 28 September 2015; Accepted 16 December 2015

Copyright (C) 2016 Ahmed Mostafa Khalil et al. This is an open access article distributed under the Creative Commons Attribution License, which permits unrestricted use, distribution, and reproduction in any medium, provided the original work is properly cited.

\section{Introduction}

We point out that assertions (3) and (4) of Theorem 36 in the paper titled "On Interval-Valued Hesitant Fuzzy Soft Sets" [1] are not true in general. We verify that the corresponding assertions in Zhang et al. [1] are incorrect by a counterexample. Finally, we introduce reasonable definitions to improve the results.

The soft set theory, proposed by Molodtsov [2], can be used as a general mathematical tool for dealing with uncertainty. Maji et al. [3] presented the concept of fuzzy soft set which is based on a combination of the fuzzy set and soft set models. Later on, Maji et al. [4] defined some operations on soft sets and showed that the distributive law of soft sets is varied. Ali et al. [5] pointed out that the distributive law of soft sets is not true in general. This implies that the distributive law of fuzzy soft sets is not true. In this paper, we show that assertions (3) and (4) of Theorem 36 proposed by Zhang et al. [1] are incorrect by a counterexample and we recorrect Theorem 36 (3) and (4) using the generalized distributive law of interval-valued hesitant fuzzy soft sets.

For the general terminologies in this paper, please refer to $[1-4,6,7]$.

Definition 1. Let $a=\left[a^{L}, a^{U}\right]=\left\{x \mid a^{L} \leq x \leq a^{U}\right\}$; then $a$ is called an interval number. In particular, $a$ is a real number, if $a^{L}=a^{U}$.

Definition 2. Let $a=\left[a^{L}, a^{U}\right]$, and let $b=\left[b^{L}, b^{U}\right]$, and $l_{a}=$ $a^{U}-a^{L}$ and $l_{b}=b^{U}-b^{L}$; then the degree of possibility of $a \geq b$ is defined as

$$
p(a \geq b)=\max \left\{1-\max \left(\frac{b^{U}-a^{L}}{l_{a}+l_{b}}, 0\right), 0\right\} .
$$

Similarly, the degree of possibility of $b \geq a$ is defined as

$$
p(b \geq a)=\max \left\{1-\max \left(\frac{a^{U}-b^{L}}{l_{a}+l_{b}}, 0\right), 0\right\} .
$$

Definition 3. Suppose that $U$ is an initial universe set, $E$ is a set of parameters, $P(U)$ is the power set of $U$, and $A \subset E$. A pair $(F, A)$ is called soft set over $U$, where $F$ is a mapping given by $F: A \rightarrow P(U)$.

Definition 4. A pair $(F, A)$ is called a fuzzy soft set over $U$, if $A \subseteq E$ and $\widetilde{F}: A \rightarrow F(U)$, where $F(U)$ is the set of all fuzzy subsets of $U$.

Definition 5. Let $X$ be a fixed set, and let Int $[0,1]$ be the set of all closed subintervals of $[0,1]$. An interval-valued hesitant fuzzy set (IVHFS, for short) $\widetilde{A}$ on $X$ is defined as

$$
\widetilde{A}=\left\{\left\langle x, h_{\widetilde{A}}(x)\right\rangle \mid x \in X\right\},
$$

where $h_{\widetilde{A}}(x): X \rightarrow \operatorname{Int}[0,1]$ denotes all possible intervalvalued membership degrees of the element $x \in X$ to $\widetilde{A}$.

For convenience, we call $h_{\widetilde{A}}(x)$ an interval-valued hesitant fuzzy element (IVHFE, for short). The set of all intervalvalued hesitant fuzzy sets on $U$ is denoted by $\operatorname{IVHF}(U)$. We can note that an IVHFS $\widetilde{A}$ can be seen as an interval-valued 
fuzzy set if there is only one element in $h_{\widetilde{A}}(x)$, which indicates that interval-valued fuzzy sets are a special type of IVHFSs.

Definition 6. Let $h_{1}$ and $h_{2}$ be two IVHFSs; then one has the following:
(1) $h_{1} \cup h_{2}=\left\{\left[\gamma_{1}^{-} \vee \gamma_{2}^{-}, \gamma_{1}^{+} \vee \gamma_{2}^{+}\right] \mid \gamma_{1} \in h_{1}, \gamma_{2} \in h_{2}\right\}$,
(2) $h_{1} \cap h_{2}=\left\{\left[\gamma_{1}^{-} \wedge \gamma_{2}^{-}, \gamma_{1}^{+} \wedge \gamma_{2}^{+}\right] \mid \gamma_{1} \in h_{1}, \gamma_{2} \in h_{2}\right\}$.

Definition 7. Let $(U, E)$ be a soft universe and $A \subseteq E$. A pair $\widetilde{S}=(\widetilde{F}, A)$ is called an interval-valued hesitant fuzzy soft set over $U$, where $\widetilde{F}$ is a mapping given by $\widetilde{F}: A \rightarrow \operatorname{IVHF}(U)$.

An interval-valued hesitant fuzzy soft set is a parameterized family of interval-valued hesitant fuzzy subsets of $U$. That is to say, $\widetilde{F}(e)$ is an interval-valued hesitant fuzzy subset in $U$, $\forall e \in A$. Following the standard notations, $\widetilde{F}(e)$ can be written as

$$
\widetilde{F}(e)=\{\langle x, \widetilde{F}(e)(x)\rangle: x \in U\} .
$$

Sometimes we write $\widetilde{F}$ as $(\widetilde{F}, E)$. If $A \subseteq E$, we can also have an interval-valued hesitant fuzzy soft $\operatorname{set}(\widetilde{F}, A)$.

Definition 8. Let $U$ be an initial universe and let $E$ be a set of parameters. Supposing that $A, B \subseteq E$ and $(\widetilde{F}, A)$ and $(\widetilde{G}, B)$ are two interval-valued hesitant fuzzy soft sets, one says that $(\widetilde{F}, A)$ is an interval-valued hesitant fuzzy soft subset of $(\widetilde{G}, B)$ if and only if

(1) $A \subseteq B$,

(2) $\gamma_{1}^{\sigma(k)} \leq \gamma_{2}^{\sigma(k)}$,

where, for all $e \in A, x \in U, \gamma_{1}^{\sigma(k)}$ and $\gamma_{2}^{\sigma(k)}$ stand for the $k$ th largest interval number in the IVHFEs $\widetilde{F}(e)(x)$ and $\widetilde{G}(e)(x)$, respectively.

In this case, we write $(\widetilde{F}, A) \sqsubseteq(\widetilde{G}, B) .(\widetilde{F}, A)$ is said to be an interval-valued hesitant fuzzy soft super set of $(\widetilde{G}, B)$ if $(\widetilde{G}, B)$ is an interval-valued hesitant fuzzy soft subset of $(\widetilde{F}, A)$. We denote it by $(\widetilde{F}, A) \sqsupseteq(\widetilde{G}, B)$.

Definition 9. Let $(\widetilde{F}, A)$ and $(\widetilde{G}, B)$ be two interval-valued hesitant fuzzy soft sets. Now $(\widetilde{F}, A)$ and $(\widetilde{G}, B)$ are said to be interval-valued hesitant fuzzy soft equal if and only if

(1) $(\widetilde{F}, A) \sqsubseteq(\widetilde{G}, B)$,

(2) $(\widetilde{G}, B) \sqsubseteq(\widetilde{F}, A)$,

which can be denoted by $(\widetilde{F}, A)=(\widetilde{G}, B)$.

Definition 10. Let $(\widetilde{F}, A)$ and $(\widetilde{G}, B)$ be two interval-valued hesitant fuzzy soft sets over $U$. The “ $(\widetilde{F}, A)$ AND $(\widetilde{G}, B)$," denoted by $(\widetilde{F}, A) \wedge(\widetilde{G}, B)$, is defined by

$$
(\widetilde{F}, A) \wedge(\widetilde{G}, B)=(\widetilde{H}, A \times B),
$$

where, for all $(\alpha, \beta) \in A \times B$,

$$
\begin{aligned}
\widetilde{H}(\alpha, \beta) & =\{\langle x, \widetilde{H}(\alpha, \beta)(x)\rangle: x \in U\} \\
& =\{\langle x, \widetilde{F}(\alpha)(x) \cap \widetilde{G}(\beta)(x)\rangle: x \in U\} .
\end{aligned}
$$

Definition 11. Let $(\widetilde{F}, A)$ and $(\widetilde{G}, B)$ be two interval-valued hesitant fuzzy soft sets over $U$. The " $(\widetilde{F}, A)$ OR $(\widetilde{G}, B)$," denoted by $(\widetilde{F}, A) \vee(\widetilde{G}, B)$, is defined by

$$
(\widetilde{F}, A) \vee(\widetilde{G}, B)=(\widetilde{I}, A \times B)
$$

where, for all $(\alpha, \beta) \in A \times B$,

$$
\begin{aligned}
\widetilde{I}(\alpha, \beta) & =\{\langle x, \widetilde{I}(\alpha, \beta)(x)\rangle: x \in U\} \\
& =\{\langle x, \widetilde{F}(\alpha)(x) \cup \widetilde{G}(\beta)(x)\rangle: x \in U\} .
\end{aligned}
$$

\section{Counterexample}

We begin this section with Theorem 12 below, originally proposed as Theorem 36 in Zhang et al. [1] and provide a counterexample to show that assertions (3) and (4) are not true.

Theorem 12 (see $[1])$. Let $(\widetilde{F}, A),(\widetilde{G}, B)$, and $(\widetilde{H}, C)$ be three interval-valued hesitant fuzzy soft sets over $U$. Then one has the following:

(1) $(\widetilde{F}, A) \wedge((\widetilde{G}, B) \wedge(\widetilde{H}, C))=((\widetilde{F}, A) \wedge(\widetilde{G}, B)) \wedge(\widetilde{H}, C)$,

(2) $(\widetilde{F}, A) \vee((\widetilde{G}, B) \vee(\widetilde{H}, C))=((\widetilde{F}, A) \vee(\widetilde{G}, B)) \vee(\widetilde{H}, C)$,

(3) $(\widetilde{F}, A) \wedge((\widetilde{G}, B) \vee(\widetilde{H}, C))=((\widetilde{F}, A) \wedge(\widetilde{G}, B)) \vee((\widetilde{F}, A) \wedge$ $(\widetilde{H}, C))$,

(4) $(\widetilde{F}, A) \vee((\widetilde{G}, B) \wedge(\widetilde{H}, C))=((\widetilde{F}, A) \vee(\widetilde{G}, B)) \wedge((\widetilde{F}, A) \vee$ $(\widetilde{H}, C))$.

The following example shows that assertions (3) and (4) of Theorem 12 above are not true in general.

Example 13. Let $U=\left\{x_{1}, x_{2}\right\}$ be a set of two houses and let $E=\left\{e_{1}, e_{2}, e_{3}, e_{4}, e_{5}, e_{6}\right\}$ be a set of parameters, which stand for expensive, beautiful, cheap, size, location, and in the green surroundings, respectively. Consider $A, B$, and $C$ to be subsets of $E$, where $A=\left\{e_{1}, e_{2}\right\}=\{$ expensive, beautiful $\}, B=$ $\left\{e_{3}, e_{4}\right\}=\{$ cheap, size $\}$, and $C=\left\{e_{5}, e_{6}\right\}=\{$ location, in the green surroundings $\}$. Suppose that $(\widetilde{F}, A),(\widetilde{G}, B)$, and $(\widetilde{H}, C)$ are three interval-valued hesitant fuzzy soft sets defined by

$$
\begin{gathered}
\widetilde{F}\left(e_{1}\right)=\left\{\left\langle x_{1},\{[0.2,0.4],[0.5,0.7]\}\right\rangle,\right. \\
\left.\left\langle x_{2},\{[0.4,0.8],[0.5,0.8]\}\right\rangle\right\}, \\
\widetilde{F}\left(e_{2}\right)=\left\{\left\langle x_{1},\{[0.3,0.5],[0.6,0.7]\}\right\rangle,\right. \\
\left.\left\langle x_{2},\{[0.1,0.3],[0.5,0.9]\}\right\rangle\right\}, \\
\widetilde{G}\left(e_{3}\right)=\left\{\left\langle x_{1},\{[0.4,0.6],[0.8,0.9]\}\right\rangle,\right. \\
\left.\left\langle x_{2},\{[0.2,0.3],[0.4,0.5]\}\right\rangle\right\},
\end{gathered}
$$




$$
\begin{gathered}
\widetilde{G}\left(e_{4}\right)=\left\{\left\langle x_{1},\{[0.6,0.9],[0.5,0.7]\}\right\rangle,\right. \\
\left.\left\langle x_{2},\{[0.4,0.6],[0.7,0.8]\}\right\rangle\right\}, \\
\widetilde{H}\left(e_{5}\right)=\left\{\left\langle x_{1},\{[0.1,0.3],[0.4,0.6]\}\right\rangle,\right. \\
\left.\left\langle x_{2},\{[0.3,0.6],[0.6,0.8]\}\right\rangle\right\}, \\
\widetilde{H}\left(e_{6}\right)=\left\{\left\langle x_{1},\{[0.4,0.5],[0.6,0.7]\}\right\rangle,\right. \\
\left.\left\langle x_{2},\{[0.7,0.8],[0.7,0.9]\}\right\rangle\right\} .
\end{gathered}
$$

By Definitions 10 and 11, the interval-valued hesitant fuzzy soft set $(\widetilde{F}, A) \wedge((\widetilde{G}, B) \vee(\widetilde{H}, C))$ has the parameter set $A \times(B \times$ $C)$ and interval-valued hesitant fuzzy soft $\operatorname{set}((\widetilde{F}, A) \wedge(\widetilde{G}, B)) \vee$ $((\widetilde{F}, A) \wedge(\widetilde{H}, C))$ has a set of parameters as $(A \times B) \times(A \times C)$. But we can not find any notion which ensures $A \times(B \times C)=$ $(A \times B) \times(A \times C)$. Hence Theorem 12 above is not true.

\section{Main Results}

Definition 14. Let $U$ be an initial universe and let $E$ be a set of parameters. For subsets $A$ and $B$ of $E$, let $(\widetilde{F}, A)$ and $(\widetilde{G}, B)$ be interval-valued hesitant fuzzy soft sets. One says that $(\widetilde{F}, A)$ is a generalized interval-valued hesitant fuzzy soft subset of $(\widetilde{G}, B)$, denoted by $(\widetilde{F}, A) \widetilde{\Sigma}_{g}(\widetilde{G}, B)$, if, for every $\alpha \in A$, there exists $\beta \in B$ such that $\gamma_{1}^{\sigma(k)} \leq \gamma_{2}^{\sigma(k)}$, where, for all $\alpha \in A$, $\beta \in B, x \in U, \gamma_{1}^{\sigma(k)}$ and $\gamma_{2}^{\sigma(k)}$ stand for the $k$ th largest interval number in the IVHFEs $\widetilde{F}(\alpha)(x)$ and $\widetilde{G}(\beta)(x)$, respectively.

Example 15. Let $U=\left\{x_{1}, x_{2}, x_{3}\right\}$ be an initial universe and let $E=\left\{e_{1}, e_{2}, e_{3}\right\}$ be a set of parameters. With $A=\left\{e_{1}, e_{2}\right\}$ and $B=\left\{e_{1}, e_{3}\right\}$, let $(\widetilde{F}, A)$ and $(\widetilde{G}, B)$ be interval-valued hesitant fuzzy soft sets defined by

$$
\begin{gathered}
\widetilde{F}\left(e_{1}\right)=\left\{\left\langle x_{1},\{[0.1,0.4],[0.3,0.7],[0.3,0.8]\}\right\rangle,\right. \\
\left\langle x_{2},\{[0.4,0.5],[0.5,0.6]\}\right\rangle, \\
\left.\left\langle x_{3},\{[0.2,0.4],[0.4,0.5]\}\right\rangle\right\}, \\
\widetilde{F}\left(e_{2}\right)=\left\{\left\langle x_{1},\{[0.2,0.5],[0.3,0.6]\}\right\rangle,\right. \\
\left\langle x_{2},\{[0.3,0.5],[0.4,0.7],[0.6,0.8]\}\right\rangle, \\
\left.\left\langle x_{3},\{[0.3,0.9],[0.5,0.8]\}\right\rangle\right\}, \\
\widetilde{G}\left(e_{1}\right)=\left\{\left\langle x_{1},\{[0.3,0.5],[0.4,0.8]\}\right\rangle,\right. \\
\left\langle x_{2},\{[0.3,0.7],[0.4,0.8]\}\right\rangle, \\
\left.\left\langle x_{3},\{[0.3,0.5],[0.3,0.7],[0.5,0.8]\}\right\rangle\right\}, \\
\widetilde{G}\left(e_{3}\right)=\left\{\left\langle x_{1},\{[0.3,0.5],[0.5,0.6],[0.8,1.0]\}\right\rangle,\right. \\
\left\langle x_{2},\{[0.55,0.6],[0.7,0.9]\}\right\rangle, \\
\left.\left\langle x_{3},\{[0.3,0.7],[0.8,0.85],[0.9,1.0]\}\right\rangle\right\} .
\end{gathered}
$$

Then $(\widetilde{F}, A) \widetilde{\Sigma}_{g}(\widetilde{G}, B)$.
Definition 16. Let $(\widetilde{F}, A)$ and $(\widetilde{G}, B)$ be interval-valued hesitant fuzzy soft sets. One says that $(\widetilde{F}, A)$ and $(\widetilde{G}, B)$ are generalized interval-valued hesitant fuzzy soft set equal, denoted by $(\widetilde{F}, A) \cong(\widetilde{G}, B)$, if $(\widetilde{F}, A) \widetilde{\Sigma}_{g}(\widetilde{G}, B)$ and $(\widetilde{G}, B) \widetilde{\Sigma}_{g}(\widetilde{F}, A)$.

Theorem 17 is the corrected version of assertions (3) and (4) of Theorem 12, originally written as Theorem 36 of Zhang et al. [1].

Theorem 17. Let $(\widetilde{F}, A),(\widetilde{G}, B)$, and $(\widetilde{H}, C)$ be three intervalvalued hesitant fuzzy soft sets over $U$. Then one has the following:

(3) $(\widetilde{F}, A) \wedge((\widetilde{G}, B) \vee(\widetilde{H}, C)) \cong((\widetilde{F}, A) \wedge(\widetilde{G}, B)) \vee((\widetilde{F}, A) \wedge$ $(\widetilde{H}, C))$,

(4) $(\widetilde{F}, A) \vee((\widetilde{G}, B) \wedge(\widetilde{H}, C)) \cong((\widetilde{F}, A) \vee(\widetilde{G}, B)) \wedge((\widetilde{F}, A) \vee$ $(\widetilde{H}, C))$.

Proof. For any $\alpha \in A, \beta \in B$, and $\gamma \in C$, we have $\widetilde{F}(\alpha) \cap(\widetilde{G}(\beta) \cup$ $\widetilde{H}(\gamma))=(\widetilde{F}(\alpha) \cap \widetilde{G}(\beta)) \cup(\widetilde{F}(\alpha) \cap \widetilde{H}(\gamma))$. Hence conclusion $(3)$ is valid. Similarly, we can prove assertion (4).

\section{Conclusions}

Zhang et al. [1] introduced interval-valued hesitant fuzzy soft set based on interval-valued hesitant fuzzy set and proposed several theorems and some operations on an interval-valued hesitant fuzzy soft set. However, we pointed out that assertion (3) and (4) of Theorem 36 [1] are not true. Using the notions of a generalized interval-valued hesitant fuzzy soft subset and fuzzy soft equal, Theorem 36 (3) and (4) of [1] is proposed and proven to be true.

\section{References}

[1] H. Zhang, L. Xiong, and W. Ma, "On interval-valued hesitant fuzzy soft sets," Mathematical Problems in Engineering, vol. 2015, Article ID 254764, 17 pages, 2015.

[2] D. Molodtsov, "Soft set theory-first results," Computers \& Mathematics with Applications, vol. 37, no. 4-5, pp. 19-31, 1999.

[3] P. K. Maji, R. Biswas, and A. R. Roy, "Fuzzy soft sets," Journal of Fuzzy Mathematics, vol. 9, no. 3, pp. 589-602, 2001.

[4] P. K. Maji, R. Biswas, and A. R. Roy, "Soft set theory," Computers and Mathematics with Applications, vol. 45, no. 4-5, pp. 555-562, 2003.

[5] M. I. Ali, F. Feng, X. Liu, W. K. Min, and M. Shabir, "On some new operations in soft set theory," Computers \& Mathematics with Applications, vol. 57, no. 9, pp. 1547-1553, 2009.

[6] N. Chen, Z. S. Xu, and M. M. Xia, "Interval-valued hesitant preference relations and their applications to group decision making," Knowledge-Based Systems, vol. 37, pp. 528-540, 2013.

[7] Z. S. Xu and Q. L. Da, “The uncertain OWA operator," International Journal of Intelligent Systems, vol. 17, no. 6, pp. 569-575, 2002. 


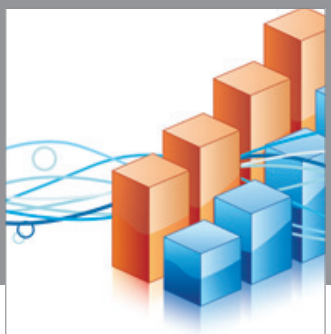

Advances in

Operations Research

vatem alat4

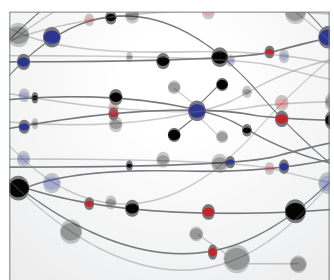

\section{The Scientific} World Journal
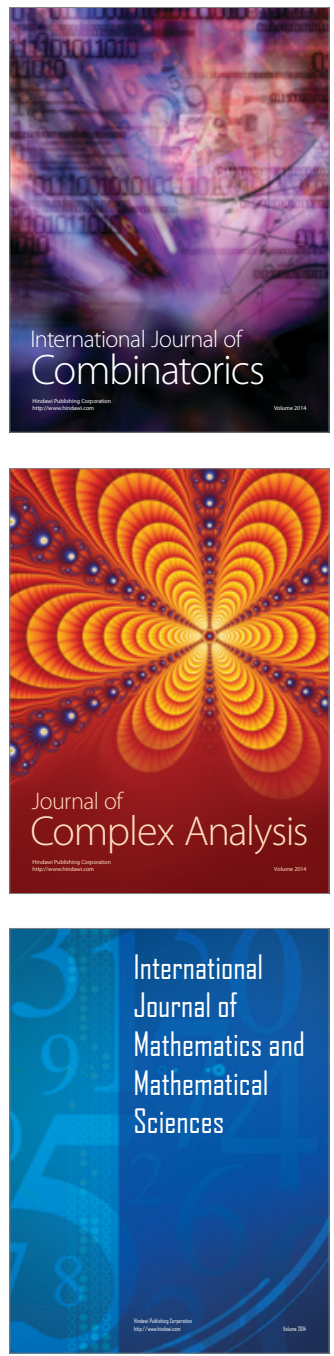
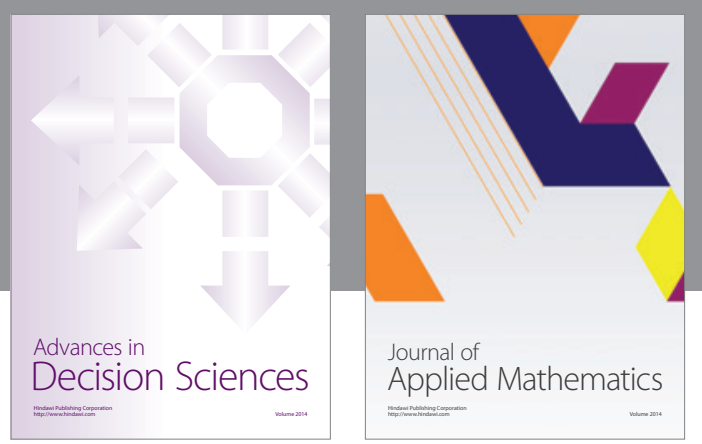

Algebra

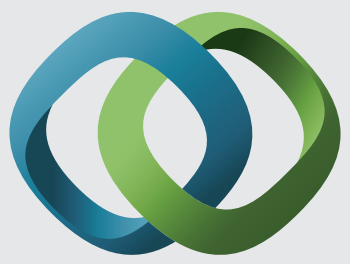

\section{Hindawi}

Submit your manuscripts at

http://www.hindawi.com
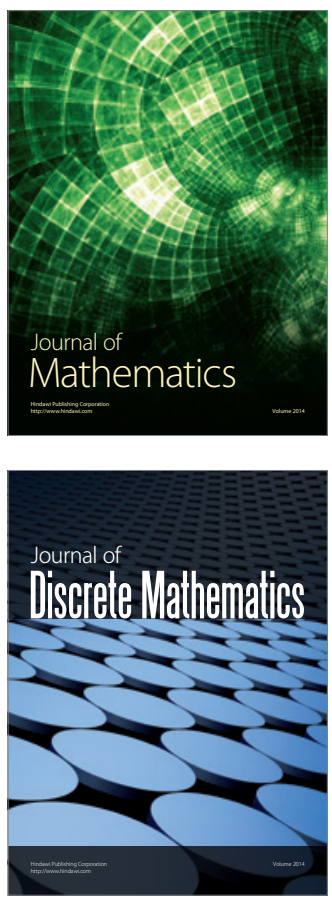

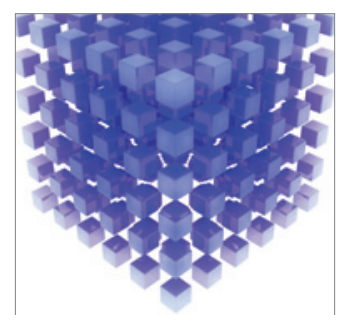

Mathematical Problems in Engineering
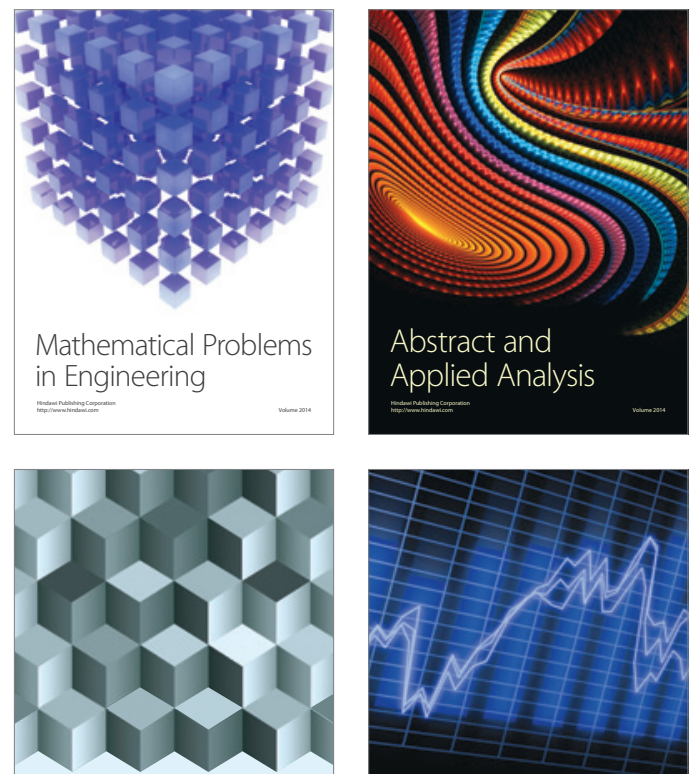

Journal of

Function Spaces

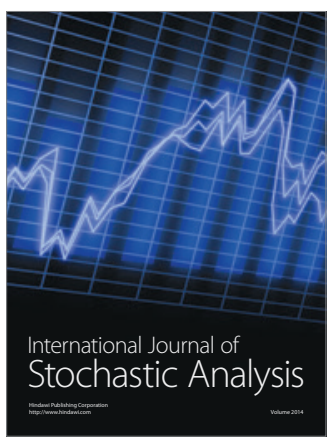

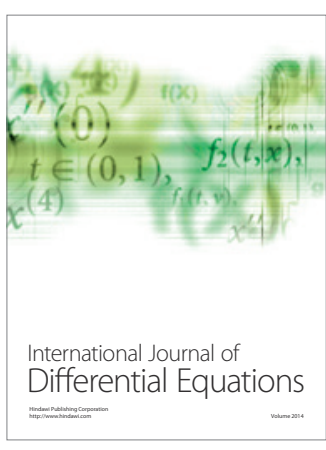
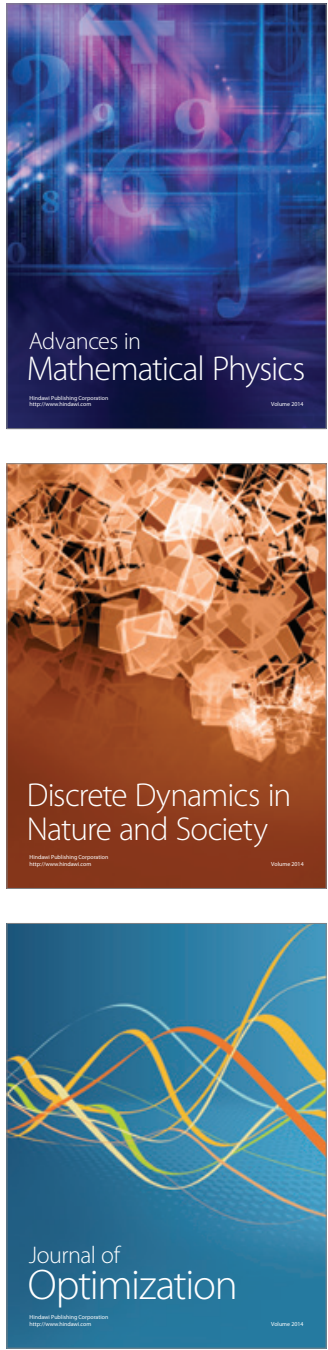